\title{
Factors Influencing Changes In Analyst Consensus Recommendations: Evidence From The Johannesburg Stock Exchange
}

Sarah Kate Mackinnon, University of Cape Town, South Africa

Ryan Kruger, University of Cape Town, South Africa

\begin{abstract}
This paper builds on Prayag and van Rensburg's (2006) study that recognised the returns that can be generated by acting on changes in consensus recommendations on the Johannesburg Stock Exchange (JSE). It identifies factors that influence analysts to revise their recommendations based on style anomalies, momentum strategies, and market sentiment. Findings indicate that analysts' recommendations on the JSE are driven by similar factors to those in other major markets with a propensity for favouring high-growth stocks with low value multiples. The results for tests in which variables are lagged for longer periods suggest that historical price changes have a more significant impact on analyst revisions than recent changes.
\end{abstract}

Keywords: Analyst; Recommendations; Revisions; Johannesburg Stock Exchange

\section{INTRODUCTION}

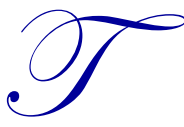

he question of whether the stock recommendations generated by financial analysts add value is complicated by the optimism bias, conflict of interest (Michaely \& Womack, 2005) and herding (Conrad, Cornell, Landsman, \& Rountree, 2006) reflected in recommendations.

Internationally, Barber, Lehavy, McNichols, and Truman (2001) found evidence to show that following analysts' recommendations could yield returns in excess of the market, but that the required rebalancing costs eroded these returns. Green (2006) highlighted that economic profits could be realized conditional on the timely reaction to recommendations, while Womack (1996) found that acting on changes in recommendation instead of the level alone could earn greater returns.

In the South African market, Hall and Millard (2002) found that acting on the level of recommendation yielded returns at least as good as the market and could limit losses, but it was van Rensburg and Prayag (2006) who recognized the significant-risk adjusted returns that could be yielded by acting on changes in analyst consensus recommendations and in particular the value of downgrades.

While research into factors that drive analyst recommendations is sparse, Michaely and Womack (2005) highlighted the large capitalization and glamour stock bias of stocks followed by analysts. Loh and Stulz (2009) identified characteristics of firms whose changes in recommendations prove more influential (including those with fewer prior earnings forecasts) and Womack (1996) suggested that changes in analyst recommendations are likely price-driven based on their timing relative to earnings announcements.

A similar analysis has yet to be conducted on the South African market and this study aims to remedy this by identifying the factors that influence the change in analyst consensus recommendations. It considers factors that have demonstrated a capacity to explain the variation in stock returns in the past and will therefore include style anomalies recognized in the South African market, including price-to-earnings, dividend-yield, cash flow-to-price (van Rensburg \& Robertson, 2003), market-to-book value (Auret \& Sinclaire, 2006), dividend and earnings growth 
(Kruger \& Toerien, 2014), and momentum (Fraser \& Page, 2000). Additional consideration will be made of other factors recognized internationally including sales-to-price (Barbee, Mukherji, \& Raines, 1996) and sentiment (Kaplanski \& Levy, 2010).

The remainder of the paper is structured as follows. Section 2 highlights prior research concerning the value of analyst recommendations and factors that are likely to influence analysts based on their empirical ability to explain the variation in stock returns. Section 3 outlines the data used and methodology while Section 4 describes the results. Section 5 concludes.

\section{PRIOR RESEARCH}

The finding that only $12 \%$ of all changes in recommendations in a sample of US analysts occurred within one day of earnings announcements (Womack, 1996), indicated that revisions are not necessarily made based on sudden factor changes or broadcasts, but are rather based on an accumulation of factors. It is also possible that changes in recommendations are driven by factors other than fundamentals such as the macroeconomic environment, relevant industry, or the stock price itself.

Factors that drive stock returns are likely to drive analyst recommendations in general and should therefore be correlated with factors that have historically demonstrated the ability to explain variation in stock returns. Within the South African Market, van Rensburg and Robertson (2003) identified relevant style characteristics by assessing 24 attributes of stocks pertaining to value, future earnings growth and rationality and neglect. They concluded that price-to-net asset value, dividend-yield, price-to-earnings, size, and cash flow-to-price were all significant as univariate predictors of price and the combination of size and price-to-earnings as a multifactor model was optimal in explaining the cross-section of stock returns.

Auret and Sinclaire (2006) suggested book-to-market as an additional style anomaly, finding that it has more explanatory power than size or price-to-earnings, but its high correlation with other explanatory variables means that van Rensburg and Roberton's model (including size and price-to-earnings) still better describes the variation in returns. Kruger and Toerien (2014) subsequently found that 12-month earnings and dividend growth are significant univariate factors in explaining the returns of JSE-listed companies.

Internationally, Barbee, Mukherji, and Raines (1996) assessed the significance of sales-to-price and debtto-equity ratios in explaining stock returns and found them to absorb the effect of both book-to-market and firm size. They highlighted Kothari, Shanken, and Sloan's (1995) study, which previously indicated the inconsistency of bookto-market in explaining the variation in returns, suggesting it is less significant than when presented originally by Fama and French (1992). The debt-to-equity ratio makes sense as a measure of risk (Bhandari, 1988) since increasing the debt-to-equity ratio would subsequently increase the risk to any common equity holder, but is considered to be captured by sales-to-price which appears to be the only measure with consistent explanatory power (Barbee, Mukherji, \& Raines, 1996).

Finally, Kaplanski and Levy (2010) identified the positive correlation between analyst recommendations and sentiment indices, which suggests that analysts (like unsophisticated investors) are affected by market sentiment. The result is most significant during periods of negative sentiment and more likely to occur when stock is considered difficult to evaluate.

Interestingly, while one could reasonably expect that analyst recommendations should be driven by the same factors that drive return prediction cited above, numerous studies have ascertained that firms that analysts tend to make recommendations for have a large capitalization bias (appropriately reflecting the investment opportunity set), and tend to be growth stocks with glamour characteristics such as high positive price momentum, high volume, greater past sales growth, and higher expected long term earnings growth. ${ }^{1}$ This would suggest that the stocks analysts recommend demonstrate characteristics that run contrary to the predictive signals for stock returns typically highlighted in the literature (Jegadeesh, Kim, Krische, \& Lee, 2004). In addition Chan, Jegadeesh, and Lakonishok

${ }^{1}$ See for example Jegadeesh, Kim, Krische, and Lee (2004) and Michaely and Womack (2005). 
(1999) found that stocks with strong buy recommendations exhibit higher price momentum relative to stocks with strong sell recommendations. Loh and Stulz (2009) identified common characteristics of the firms whose changes in recommendations proved influential to investors. They identified these firms as smaller, with higher institutional ownership, lower total and idiosyncratic volatility, lower stock turnover, and lower number of prior earnings forecasts.

\section{DATA AND METHODOLOGY}

\subsection{Data}

Analyst consensus recommendations of 92 companies on the Johannesburg Stock Exchange (JSE) for the period spanning January 2002 to December 2009 were obtained from I-Net Bridge. The recommendations were filtered to include only changes that lasted at least one month so that any change considered was more likely to reflect an adjustment in analysts' perception of stock and exclude frequent changes of analysts whom are not influential but are reflected through aggregation of recommendations.

The total number of changes in analyst consensus recommendations observed over the sample period amounted to $1,767.590(33.4 \%)$ of these changes in recommendation persisted for at least one month and, of those changes, $71(12.1 \%)$ represent changes between sell and hold, while $519(87.9 \%)$ reflect changes between buy and hold. The proportion of observations concerning the relevant changes reflect Michaely and Womack's (2005) documented optimism bias of analyst recommendations as well as their reluctance to downgrade stock to sell. For purposes of this study we focus on the changes in recommendation suggested to hold the most information content changes from hold to buy and hold to sell.

Daily total returns data was obtained from Thomsons Datastream for each of the companies in question as was company-specific time series data pertaining to the factors to be tested: price-to-earnings, dividend yield, market-to-book value, gross profit margin, sales-to-price, cash flow-to-price, the change in 12-month earnings per share, the change in 12-month dividends per share, dividend payout ratio, return on equity, and return on assets. In addition, percentage changes in the historical levels of the Business Confidence Index (BCI), considered to reflect market sentiment, over the applicable period were obtained.

Table 1: Factors to be Considered as Explanatory Variables in the Analysis

\begin{tabular}{|l|l|}
\hline \multicolumn{1}{|c|}{ A brief description of the proposed explanatory variables along with the relevant acronyms used throughout the analysis. } \\
\hline 1. BCI & Bescription \\
\hline 2. THREEMOM & Three-month momentum - performance of stock over the previous three months \\
\hline 3. TWELVEMOM & Twelve-month momentum - performance of stock over the previous twelve months \\
\hline 4. RISK & Risk of stock calculated based on the standard deviation of returns over the previous 12 months \\
\hline 5. PE & Price-to-earnings ratio \\
\hline 6. DY & Dividend yield \\
\hline 7. MTBV & Market-to-book value \\
\hline 8. GPMARGIN & Gross profit margin \\
\hline 9. SALESP & Sales-to-Price \\
\hline 10. CFTP & Cash flow-to-price \\
\hline 11. TWELVEEARNG & The 12-month growth in DPS \\
\hline 12. TWELVEDIVG & The 12-month growth in EPS \\
\hline 13. PAYOUT & The dividend pay-out ratio of the firm \\
\hline 14. ROE & The firm's return on equity ratio \\
\hline 15. ROA & The firm's return on assets ratio \\
\hline
\end{tabular}

Four separate databases were generated to reflect different lags on the company-specific factors (with respect to the change in recommendation) and the form of factor considered. For the first database, changes in recommendations were associated with company-specific factors that were lagged by one month. In the second database, company-specific factors were lagged by six months. While the lag of one month reflects common practice in analysis of style attributes to ensure that information may be considered sufficiently disseminated 
amongst analysts, the lag of six months allows for the consideration that changes in recommendations are not influenced by recent company-specific factors but by either historical factors or recent changes in analyst's recommendations (particularly leader analysts). This is in response to a study by Conrad et al. (2006) suggesting that analysts delay changing their recommendation on stock (especially downgrading) until the change is corroborated by a change in price and that recommendations demonstrate herding.

In the third database, company-specific factors were specified as relative measures based on the improvement (or decline) of the factor since the last change in recommendation. Lev and Thiagarajan (1993) found that earnings forecasting could be improved by the use of financial signals based on changes in fundamental variables in relation to one another and therefore analysis of the improvement (or decline) in company-specific factors is relevant. The fourth database was also based on relative measures but lagged by six months.

Finally, all databases considered both the entire observation period (2002-2009) as well as a subset (20022007) considered to be a more stable market environment due to its exclusion of the recent financial crisis. The importance of evaluating company-specific financial indicators within their respective macroeconomic environments were highlighted by Lev and Thiagarajan (1993) and stressed by Kruger and Toerien (2014) in the context of style anomalies.

\subsection{Regression Analysis}

Regression analysis was performed to identify which factors (if any) could explain a change in consensus recommendation. The dependent variable is a binary response variable $\left(z_{i}\right)$ for which logistic regression modelling is appropriate and was modelled based on upgrades from hold to buy relative to downgrades from hold to sell.

Logistic regression and the use of a binomial link function (discussed below) required that observations reflecting similar characteristics with respect to the proposed explanatory variables, be grouped. Where the improvement (or decline) of factors was considered, observations were grouped to reflect a decline of more than 5\%, a change within a band of 5\%, and an improvement greater than 5\%. In this way, groups that differed with respect to the combination of factor levels they characterized (from here on referred to as categorical groups) were established and observations were sorted accordingly.

Each change in recommendation can be described as a binary response variable such that:

$\begin{array}{lll}z_{i} & =1 & \text { if stock upgraded with probability } \mathrm{p} \\ & =0 & \text { if stock downgraded with probability (1-p) }\end{array}$

where $\mathrm{p}$ is approximated for each categorical group by the proportion of upgrades observed such that:

$\frac{Y}{n}=\frac{\sum_{i=0}^{n} z_{i}}{n}$

and $\mathrm{Y}$, the number of observed upgrades within each categorical group (representing $\mathrm{n}$ observations), has a binomial distribution.

$Y \sim B(n, p)$

The dependent variable, assumed to have a binomial distribution, is therefore appropriately modelled through a generalized linear regression. $\mathrm{P}$, continuous on the range $[0 ; 1]$, is transformed to reflect the potential range of the linear combination of explanatory variables on the interval $(-\infty ; \infty)$ through the use the logistic link function (considered the most appropriate link for binary responses). Parameters are estimated using the method of maximum likelihood (since the error term is not normally distributed as it is associated with the distribution of the dependent variable) and factors are considered significant based on a level of 5\%. 
The logistic regression equation is specified as:

$$
\begin{gathered}
\log \left(\frac{\hat{p}_{i}}{1-\hat{p}_{i}}\right)=\beta_{0}+\beta_{1} X_{1 i}+\cdots+\beta_{k} X_{k i} \\
\frac{\hat{p}_{i}}{1-\widehat{p}_{l}}=e^{\beta_{0}+\beta_{1} X_{1 i}+\cdots+\beta_{k} X_{k i}}
\end{gathered}
$$

Where $\hat{p}_{i}$ is the estimated probability of an upgrade in stock associated with categorical group $\mathrm{i}, \beta_{j}$ represents the sensitivity to factor $\mathrm{j}$ such that for a one unit increase in factor $\mathrm{j}$ the odds of an upgrade improve by $e^{\beta_{j}}$ and $X_{j i}$ is the factor value of explanatory variable $\mathrm{k}$ for categorical group $\mathrm{i}$.

Explanatory variables included the BCI and company-specific factors defined by appropriate intervals over their range of values. Such intervals were coded to reflect ranking and enabled these factors to be recognized as continuous variables in the analysis, while at the same time limiting the number of possible values for each factor to ensure a sufficient sample size for each categorical group.

The regression method used accounts for missing values by excluding them from the analysis. Therefore, the datasets used for each univariate model differed in size and bivariate models could not be compared to their respective nested models through commonplace F-tests. The comparison of models that are based on different datasets is possible through the use of the Akaike Information Criterion (AIC), which favours the smallest residual variance and penalizes the addition of further explanatory variables:

$\mathrm{AIC}=2 \mathrm{k}-2 \ln (\mathrm{L})$

where $\mathrm{k}$ indicates the number of parameters in the statistical model, $\mathrm{n}$ reflects the number of observations the analysis is based on and $\mathrm{L}$ indicates the maximized value of the likelihood function for the estimated model.

Forward selection methods were used to identify the optimal model for changes from hold to buy relative to hold to sell over the periods considered. This process involves starting with simple univariate models, identifying the best one and adding additional explanatory variables on the basis that they improve the model according to specified criterion. The AIC criterion was used to establish model ranking.

The linear components of the models identified were then checked by plotting residuals versus fitted values in order to establish whether the form of the linear component was adequate in explaining variation.

\section{RESULTS}

\subsection{Univariate Logistic Regressions}

Logistic regression of binary responses is limited to the analysis of mutually exclusive events such as a change in recommendation that cannot be both an upgrade and a downgrade. Therefore the interpretation of the results amounts to factors that increase the odds of an upgrade from hold to buy relative to a downgrade from hold to sell. 
Table 2: Results for the Logistic Regressions for Changes in Recommendations from Hold to Buy Relative to Hold to Sell against Factors Lagged by One Month

\begin{tabular}{|c|c|c|c|c|}
\hline \multirow{2}{*}{\multicolumn{5}{|c|}{$\begin{array}{l}\text { Logistic regression analysis is conducted for company-specific factors lagged by one mor } \\
\text { recommendation considered. The regressions aim to determine those factors which increa } \\
\text { to buy relative to a downgrade from hold to sell. Results which are significant at the } 5 \% 1 \\
\text { level by } * * \text {, and at the } 0.1 \% \text { level by } * * * \text {. } \\
\text { Company-Specific Factors Lagged By } 1 \text { Month }\end{array}$}} \\
\hline & & & & \\
\hline & \multicolumn{2}{|c|}{$2002-2007$} & \multicolumn{2}{|c|}{ 2002-2009 } \\
\hline & Estimate & P-Value & Estimate & P-Value \\
\hline BCI & $-0,310$ & 0,463 & $-0,350$ & 0,357 \\
\hline THREEMOM & 0,275 & 0,379 & 0,120 & 0,626 \\
\hline TWELVEMOM & 0,820 & 0,019* & 0,297 & 0,283 \\
\hline RISK & 0,427 & 0,579 & $-0,221$ & 0,649 \\
\hline DY & $-1,278$ & $0,000 * * *$ & $-1,012$ & $0,000 * * *$ \\
\hline GPMARGIN & $-0,143$ & 0,782 & $-0,101$ & 0,810 \\
\hline MTBV & 1,568 & $0,005 * *$ & 1,121 & 0,016* \\
\hline SALESP & $-0,201$ & 0,463 & $-0,132$ & 0,606 \\
\hline $\mathrm{PE}$ & 0,900 & 0,039* & 0,792 & $\mathbf{0 , 0 3 7 *}$ \\
\hline CFTP & $-0,238$ & 0,468 & $-0,067$ & 0,813 \\
\hline TWELVEEARNG & 1.250 & $0.00097 * * *$ & 1.099 & $0.00151 * *$ \\
\hline TWELVEDIVG & 0.607 & 0.263 & 0.551 & 0.240 \\
\hline PAYOUT & -0.417 & 0.162 & -0.128 & 0.640 \\
\hline ROE & 1.412 & $0.00118 * *$ & 0.859 & $0.02138 *$ \\
\hline $\mathrm{ROA}$ & 1.160 & $0.0177 *$ & 0.873 & 0.0338* \\
\hline
\end{tabular}

Notes: Results which are significant at the $5 \%$ level are indicated by *, at the $1 \%$ level by **, and at the $0.1 \%$ level by ***.

Factors identified as significant for upgrades from hold to buy relative to hold to sell were twelve-month momentum, dividend yield, market-to-book value, price-to-earnings, growth in 12-month earnings, return on equity, and return on assets and were all (barring twelve-month momentum) consistent over both sample periods considered. While each of these factors (apart from return on equity and return on assets) has been identified in the South African market as a style anomaly, analysis of the parameter estimates for price-to-earnings and market-tobook value suggest that higher multiples influence stock upgrades while estimates for dividend yield indicate that lower multiples influence stock upgrades. This contradicts the literature surrounding these respective style anomalies, which suggests buying undervalued firms based on their low price-to-earnings and market-to-book value ratios and high dividend yield ratios. In addition, twelve-month momentum has historically suggested meanreversion and has therefore been negatively correlated with returns, contrary to the positive relationship identified here. These results, as well as the presence of the 12-month earnings growth factor, agree with findings for the US market which suggest that analysts tend to favour glamour stocks which have low value multiples and high growth. ${ }^{2}$

A further consideration is the lag assumed between an analyst changing their stock recommendations away from the existing consensus recommendation and the actual change in consensus recommendation. While Prayag and van Rensburg's (2006) study of the period from 2000 to 2003 suggests that abnormal returns can be earned using strategies based on acting on changes in consensus recommendations, there is a possibility that some of the price move has already occurred by the time the consensus recommendation changes. We therefore repeat the analysis with the database in which the company-specific factors were lagged by six months in relation to the date that the recommendation was changed. The results of the analysis are presented in Table 3, below.

\footnotetext{
${ }^{2}$ See Jegadeesh, Kim, Krische, and Lee (2004) and Michaely and Womack (2005).
} 
Table 3: Results for the Logistic Regressions for Changes in Recommendations from Hold to Buy Relative to Hold to Sell against Factors Lagged by Six Months

\begin{tabular}{|c|c|c|c|c|}
\hline \multirow{3}{*}{\multicolumn{5}{|c|}{$\begin{array}{l}\text { Logistic regression analysis is conducted for company-specific factors lagged by six mo } \\
\text { recommendation considered. The regressions aim to determine those factors which increas } \\
\text { to buy relative to a downgrade from hold to sell. Results which are significant at the } 5 \% \\
\text { level by } * * \text {, and at the } 0.1 \% \text { level by } * * \text {. } \\
\text { Company-Specific Factors Lagged By } 6 \text { Months }\end{array}$}} \\
\hline & & & & \\
\hline & & & & \\
\hline & Estimate & P-Value & Estimate & P-Value \\
\hline THREEMOM & 0,191 & 0,527 & $-0,120$ & 0,654 \\
\hline TWELVEMOM & 1,195 & $0,001 * * *$ & 0,614 & $\mathbf{0 , 0 2 0} *$ \\
\hline RISK & 0,257 & 0,692 & 0,329 & 0,559 \\
\hline DY & $-1,906$ & $\mathbf{0 , 0 0 0 * * *}$ & $-1,467$ & $0,000 * * *$ \\
\hline GPMARGIN & $-0,195$ & 0,731 & $-0,193$ & 0,666 \\
\hline MTBV & 1,942 & $\mathbf{0 , 0 0 1} * *$ & 1,088 & $\mathbf{0 , 0 3 0} *$ \\
\hline SALESP & $-0,330$ & 0,241 & $-0,192$ & 0,456 \\
\hline $\mathrm{PE}$ & 0,358 & 0,411 & 0,449 & 0,222 \\
\hline CFTP & $-0,191$ & 0,537 & 0,060 & 0,836 \\
\hline TWELVEEARNG & 1.408 & $0.000136 * * *$ & 1.016 & $0.00120 * *$ \\
\hline TWELVEDIVG & 1.680 & 0.988 & 1.822 & 0.078 \\
\hline PAYOUT & -0.431 & 0.146 & -0.206 & 0.452 \\
\hline ROE & 0.519 & 0.173164 & 0.494 & 0.160 \\
\hline ROA & 1.088 & $0.0239 *$ & 0.799 & $0.0472 *$ \\
\hline
\end{tabular}

Notes: Results which are significant at the $5 \%$ level are indicated by *, at the $1 \%$ level by **, and at the $0.1 \%$ level by ***.

Factors identified as significant for upgrades from hold to buy based on company-specific data lagged by six months were twelve-month momentum, dividend-yield, market-to-book value, 12-month earnings growth, and return on assets and all significant variables were consistent over both periods considered. The absolute parameter estimates of the price factors are consistently and considerably higher than those based on the factors lagged by one month suggesting that historical price moves are more influential in improving the odds of a change in consensus recommendation than more recent price moves. This may indicate that more experienced analysts with higher leader-follower ratios from larger brokers make recommendation changes away from consensus, which is reflected later in consensus recommendations due to either herding or other analysts reacting to the same information. Analysts with these characteristics have been previously identified as having more influential changes in recommendations (Loh \& Stultz, 2009).

Lev and Thiagarajan (1993) demonstrated the importance of using relative measures through their identification of financial indicators that improved earnings forecasts. These indicators were based on the improvement (or decline) of financial variables in relation to the improvement (or decline) of other financial variables. It is therefore relevant to consider factors' improvement (or decline) since the last recommendation change.

Company-specific factors for both changes considered (new change in recommendation and previous change in recommendation) were lagged by one month with respect to the change considered. The analysis was repeated based on these changes in company-specific factors being lagged by at least six months. This enabled analysis of changes in company-specific factors that leading analysts could possibly be responding to or factors that influence analysts decision to change recommendation that are only realized in conjunction with a price move. Based on the intervals on which improvements (or declines) were implemented, parameters estimates imply the exponential increase (or decrease) in odds of an upgrade (or upgrade from hold to buy) for the improvement of a factor by at least $5 \%$ (or a decline of a factor by at least $5 \%$ ). Factors that already represent changes in one of the underlying metrics were excluded from the analysis. The results are summarized in Table 4. 
Table 4: Results for the Logistic Regressions of Changes in Factors Relative to Changes in Recommendations from Hold to Buy Relative to Hold to Sell

Logistic regression analysis is conducted for the percentage improvement (or decline) of company-specific factors lagged by at least one month or at least six months with respect to the change in recommendation considered. The regressions aim to determine those factors which increase the odds of an upgrade from hold to buy relative to a downgrade from hold to sell. Results which are significant at the $5 \%$ level are indicated by $*$, at the $1 \%$ level by $* *$, and at the $0.1 \%$ level by $* * *$.

\begin{tabular}{|c|c|c|c|c|}
\hline \multicolumn{5}{|c|}{ Change In Company-Specific Factors Lagged 1 Months } \\
\hline & \multicolumn{2}{|c|}{$2002-2007$} & \multicolumn{2}{|c|}{ 2002-2009 } \\
\hline Change In & Estimate & P-Value & Estimate & P-Value \\
\hline DY & 0,072 & 0,857 & 0,091 & 0,780 \\
\hline GPMARGIN & 2,021 & $0,042 *$ & 1,588 & $\mathbf{0 , 0 2 2} *$ \\
\hline MTBV & 0,721 & 0,055 & 0,427 & 0,166 \\
\hline SALESP & $-0,447$ & 0,296 & 0,109 & 0,746 \\
\hline $\mathrm{PE}$ & 0,116 & 0,767 & $-0,003$ & 0,993 \\
\hline CFTP & 0,313 & 0,408 & 0,080 & 0,798 \\
\hline PAYOUT & -0.587 & 0.271 & -0.057 & 0.903 \\
\hline ROE & 0.445 & 0.415 & 0.626 & 0.157 \\
\hline ROA & 1.208 & $0.010 *$ & 1.253 & $0.002 * *$ \\
\hline \multicolumn{5}{|c|}{ Change In Company-Specific Factors Lagged 6 Months } \\
\hline & \multicolumn{2}{|c|}{$2002-2007$} & \multicolumn{2}{|c|}{$2002-2009$} \\
\hline Change In & Estimate & P-Value & Estimate & P-Value \\
\hline DY & 0.244 & 0.538 & -0.074 & 0.824 \\
\hline GPMARGIN & 1.657 & 0.133 & 1.781 & 0.032* \\
\hline MTBV & 0.332 & 0.380 & 0.283 & 0.377 \\
\hline SALESP & 0.030 & 0.944 & 0.184 & 0.595 \\
\hline $\mathrm{PE}$ & -0.553 & 0.157 & -0.220 & 0.486 \\
\hline CFTP & $-0,184$ & 0,443 & $-0,112$ & 0,566 \\
\hline PAYOUT & 0.188 & 0.746 & 0.304 & 0.577 \\
\hline ROE & 0.504 & 0.320 & 0.058 & 0.889 \\
\hline ROA & 0.4860 & 0.238 & 0.062 & 0.861 \\
\hline
\end{tabular}

Notes: Results which are significant at the $5 \%$ level are indicated by *, at the $1 \%$ level by **, and at the $0.1 \%$ level by ***.

The only significant factors, based on their improvements since the last recommendation change, for upgrades from hold to buy lagged by one month were gross profit margin and return on assets, over both periods considered. It is intuitive to consider gross profit margin based on its improvement (or decline) and not its absolute figure since different industries exhibit different margin ranges. Similarly, ROA is a measure of efficiency and is best interpreted based on changes over time rather than point estimates in time. For company-specific factors lagged by six months, only gross profit margin was significant and only for the period which includes the crisis.

\subsection{Multivariate Logistic Regressions}

Lastly, we construct a multivariate logistic regression model that best explains changes in analyst recommendations from hold to buy relative to hold to sell over the stable period considered in the earlier analysis. The model identifies the individual company specific factor which yields the lowest AIC score. A stepwise process is then employed to identify the additional factors to be added at each step which further improve (lower) the model scores. The results are presented in Table 5.

Table 5: Stepwise Models for Changes in Analyst Recommendations from Hold to Buy Relative to Hold to Sell Results of building a model, based on minimizing the AIC, for changes from hold to buy relative to hold to sell over the stable period for factors lagged by one and six months. The model employs a stepwise approach in identifying the best base variable and then adding additional variables that improve the AIC score into a multivariate model.

\begin{tabular}{|l|c|}
\multicolumn{1}{|c|}{ Company-Specific Factors Lagged By 1 Month } & AIC \\
\hline$\sim$ GPMARGIN & 90.354 \\
\hline$\sim$ GPMARGIN + TWELVEEARNG & 72.026 \\
\hline$\sim$ GPMARGIN + TWELVEEARNG + MTBV & 54.553 \\
\hline$\sim$ GPMARGIN + TWELVEEARNG + MTBV + DY & 45.826 \\
\hline$\sim$ GPMARGIN + TWELVEEARNG + MTBV + DY + ROE & 41.417 \\
\hline$\sim$ GPMARGIN + TWELVEEARNG + MTBV + DY + ROE + TWELVEDIVG & 37.148 \\
\hline
\end{tabular}


Table 5 cont.

\begin{tabular}{|l|c|}
\hline \multicolumn{1}{|c|}{ Company-Specific Factors Lagged By 6 Months } & AIC \\
\hline$\sim$ GPMARGIN & 75.129 \\
\hline$\sim$ GPMARGIN + TWELVEEARNG & 57.116 \\
\hline$\sim$ GPMARGIN + TWELVEEARNG + DY & 47.094 \\
\hline$\sim$ GPMARGIN + TWELVEEARNG + DY + TWELVEDIVG & 36.803 \\
\hline$\sim$ GPMARGIN + TWELVEEARNG + DY + TWELVEDIVG + MTBV & 29.254 \\
\hline$\sim$ GPMARGIN + TWELVEEARNG + DY + TWELVEDIVG + MTBV + ROA & 25.093 \\
\hline
\end{tabular}

Note: The models employ a stepwise approach in identifying the best base variable and then adding additional variables that improve the AIC score into a multivariate model.

The optimal model based on company-specific factors lagged by one month includes gross profit margin, dividend yield, market-to-book value, return on equity and twelve-month earnings and dividend growth while the optimal model based on company specific data lagged by six months includes the same factors except for return on assets replacing return on equity. The factors for both models are consistent with the univariate factors identified in the earlier analysis apart from the inclusion of gross profit margin and growth in twelve month dividends.

While these models are optimal given the pool of explanatory variables considered, a plot of residuals versus fitted values suggests that trend in error persists in both cases and therefore the linear component is inadequate to fully describe variation. This suggests an opportunity for analysis of further factors that may be influential in prompting the re-evaluation of analyst forecasts.

\section{CONCLUSION}

This study seeks to identify factors that influence analysts to change their recommendation on stock based on logistic regression analysis of consensus recommendations over the period of 2002 to 2009. It is the first such study for the JSE and builds on research by van Rensburg and Prayag's (2009) who identified the value of investment strategies based on the use of changes in consensus.

Findings are interpreted as factors that increase the probability of an upgrade or change in consensus recommendation from hold to buy, relative to a downgrade or change in consensus recommendation from hold to sell. The factors considered most significant were twelve-month momentum, dividend yield and market-to-book value, price-earnings ratio, 12-month earnings growth, return on equity, and return on assets. The same factors were significant when lagged by six months, apart from price-earnings ratio and return on equity. The parameter estimates of the price factors were considerably higher when based on the six-month lag, suggesting that historical price changes are more influential than recent changes in influencing recommendation revisions.

An analysis of the impact of improvements or declines in factors on recommendation revisions found that the percentage improvement (or decline) in gross profit margin and return on assets since the last change in recommendation was significant based on a one-month lag. Gross profit margin remained significant when considering changes lagged by six months.

Interpretation of the results suggests that analyst recommendations are most likely price-driven, a notion suggested by Womack (1996), and that there could be a potential lag in the change in consensus recommendation in relation to the price movement.

Model development, based on the stable period, recognized a model including gross profit margin, twelvemonth earnings and dividend growth, market-to-book value, dividend yield, and return on equity as optimal for factors lagged by one month and the same factors were found to yield the optimal multivariate model for factors lagged by six months except that return on assets was found to replace return on equity. While these factors demonstrated ability to explain variation, the trend in residuals that remains leaves room for the addition of further explanatory factors beyond the scope of those considered in this study. 


\section{AUTHOR INFORMATION}

Sarah Kate Mackinnon is a recent graduate of the University of Cape Town, having completed an Honours degree in Finance. Contact at: Sarah Kate Mackinnon, Department of Finance and Tax, University of Cape Town, Private Bag, Rondebosch, 7701, South Africa.

Ryan Kruger, Ph.D., is a Senior Lecturer in Finance and an associate and founding member of the African Collaboration for Quantitative Finance and Risk Research (ACQuFRR) at the Department of Finance and Tax, University of Cape Town, Private Bag, Rondebosch, 7701, South Africa. E-mail: ryan.kruger@uct.ac.za (Corresponding author)

\section{REFERENCES}

1. Auret, C. J., \& Sinclair, R. (2006). Book-to-market ratio and returns on the JSE. Investment Analysts Journal, 63, 31-38.

2. Barbee, W., Mukherji, S., \& Raines, G. (1996). Do sales-price and debt-equity explain stock returns better than book-market and firm size? Financial Analysts Journal, 522, 56-60.

3. Barber, B., Lehavy, R., McNichols, M., \& Trueman, B. (2001). Can investors profit from the prophets? Security analyst recommendations and stock returns. The Journal of Finance, 572, 531-564.

4. Bhandari, L. (1988). Debt-equity ratio and expected common stock returns: Empirical evidence. The Journal of Finance, 432, 507-528.

5. Boni, L., \& Womack, K. (2006). Analysts, industries, and price momentum. The Journal of Financial and Quantitative Analysis, 411, 85-109.

6. Chan, K., Jegadeesh, N., \& Lakonishok, J. (1999). The profitability of momentum strategies. Financial Analysts Journal, 80-90.

7. Conrad, J., Cornell, B., Landsman, W., \& Rountree, B. (2006). How do analyst recommendations respond to major news? The Journal of Financial and Quantitative Analysis, 411, 25-49.

8. Fama, E., \& French, K. (1992). The cross section of expected stock return. Journal of Finance, 472, 427465.

9. Fraser, E., \& Page, M. (2000). Value and momentum strategies: Evidence from the Johannesburg stock exchange. Investment Analysts Journal, 51, 25-35.

10. Green, T. (2006). The value of client access to analyst recommendations. Journal of Financial and Quantitative Analysis, 411, 1-24.

11. Hall, J. H., \& Millard, S. M. (2002). An assessment of the value of brokerage information for individual investors. Investment Analysts Journal, 55, 45-51.

12. Jegadeesh, N., Kim, J., Krische, S., \& Lee, C. (2004),. Analyzing the analysts: When do recommendations add value? The Journal of Finance, 593, 1083-1124.

13. Kadan, O., Madureira, L., Wang, R., \& Zach, T. (2012). Analysts' industry expertise. Journal of Accounting and Economics, 54(2), 95-120.

14. Kaplanski, G., \& Levy, H. (2010). Sentiment effect on analysts' recommendations: Time-series and crosssection analyses. (Unpublished).

15. Kothari, S., Shanken, J., \& Sloan, R. (1995). Another look at the cross-section of expected stock returns. The Journal of Finance, 501, 185-224.

16. Kruger, R., \& Toerien, F. (forthcoming). The consistency of equity style anomalies on the JSE during a period of market crisis. African Finance Journal.

17. Lev, B., \& Thiagarajan, S. (1993). Fundamental information analysis. Journal of Accounting Research, 312, 190-215.

18. Loh, R., \& Stultz, R. (2011). When are analyst recommendation changes influential? Review of Financial Studies, 242, 593-627.

19. Michaely, R., \& Womack, K. (2005). Brokerage recommendations: Stylized characteristics, market responses and biases. In R. Thaler (Ed), Advances in behavioural finance II. Princeton, NJ: Princeton University Press.

20. Moskowitz, T., \& Grinblatt, M. (1999). Do industries explain momentum? The Journal of Finance, 544, 1249-1290. 
21. Prayag, C., \& van Rensburg, P. (2006). The value of analysts' consensus recommendations: Evidence from South African Brokerage houses. Investment Analysts Journal, 63, 5-17.

22. Van Rensburg, P., \& Robertson, M. (2003). Style characteristics and the cross-section of JSE returns. Investments Analysts Journal, 57, 1-10.

23. Womack, K. (1996). Do brokerage analysts' recommendations have investment value? The Journal of Finance, 511, 137-167. 
NOTES 